\title{
Data Development Running Analysis in the Process of Synchronizing Patient Reference Services One-Stop Service Oriented
}

\author{
Iwan Purwanto ${ }^{1}$ \\ iwan.purwanto@ttrisakti.ac.id \\ ${ }^{1}$ Departemen of Informatika, Industrial Technology Faculty \\ Universitas Trisakti \\ Jakarta, Indonesia
}

\begin{abstract}
The service process implemented with subsidized facilities is a tiered process. Patients must undergo a treatment process at a hospital that has a lower level prior to being recommended to a higher hospital with better facilities, of course. Today the administrative process is still running using a filing system, where patients are still using files to bring patient reference data to hospital actions. The problem that arises is that in the registration process and service actions (filing) treatment that is still done manually is a barrier for patients to enjoy the service perfectly. Patients must register manually with a file from the referral hospital. The researcher tried to make a design using the distribution of data carried out on the previous illness to be transferred to a follow-up hospital, so that patients did not need to do the queue during the registration process, and the patient's track record could be taken online by the referral hospital. The Envelopment Analysis Data will record the process and forward it to the referral hospital, so that the patient does not need to do the redelivery and does not need to bring the file to the referral hospital. The level of accuracy of the data can be ascertained the quality, because the data is synchronized. This certainly makes it easy for patients to get time for action and convenience for hospital staff in the process of reviewing the patient's track record from the referring hospital.
\end{abstract}

Keywords: Patients; Hospital; Queue; Envelopment Analysis Data.

\section{Introduction}

A hospital is a professional health care institution whose services are provided by doctors, nurses and other health professionals. Hospital information management systems began to be used in the 1960's. These systems can be classified as integrated and modular systems. The integrated information system is divided into hospital general information systems, clinical information systems, management information systems, and database management systems. [1].

However, in the academic literature, these and other dimensions of various processes are only partially and selectively examined and / or linked to management decisions [2] Moreover, where various related concepts have been used, they have been placed in relation to only process management decisions selected and isolated, such as virtualization, system implementation or standardization $[3,4,5]$.

The system that refers more to manual procedures is seen as providing new problems for patients. The difficulty of obta ining the procedure for getting to the hospital of choice creates an obstacle for the patient, especially in completing the filing.

Therefore, in this study a centralized information system design was carried out only in type $\mathrm{C}$ hospitals as the upstream administrative system process. And patients do not need to bring a referral letter / document anymore to a type B hospital if they are going to carry out further treatment / services. 


\section{Process Variety in Practice}

Nowadays, the process of treatment for patients who use social health insurance must be carried out in several stages as below;

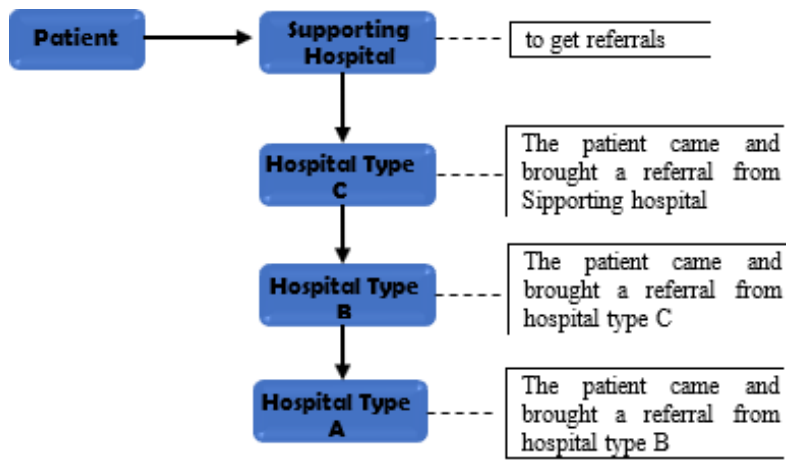

Fig 1. The cycle of repentance

In Figure 1 above, it can be explained that the patient who will undergo the treatment process, first checks and checks in the auxiliary hospital. If the condition has not improved, then head to the type $\mathrm{C}$ hospital with a referral letter from the auxiliary hospital an $\mathrm{d}$ patient supporting documents. If the type $\mathrm{C}$ hospital has not improved yet, the patient will be referred to the type $\mathrm{B}$ hospital by bringing a referral letter from the type $\mathrm{C}$ hospital followed by patient supporting documents, and if it has not improved also in the type $\mathrm{B}$ hospital, the patient will be referred to hospital type A with referral from hospital type B which is equipped with patient supporting documents.

This of course becomes a problem in itself for patients and their families. In one position the patient feels pain, on the other hand the patient is burdened with documents that must be taken to the referral hospital. Not to mention that the registration process is so long, of course it becomes a very difficult obstacle for patients.

Enyikapi the problems mentioned above, then in this study tries to develop an application system that will facilitate patients and hospital administrations in the administrative system.

\section{Discussion}

The patient administration process is still being carried out manually. Even though the process that runs in the hospital has been carried out using a computerized system. There are still gaps in error caused by humans in its operational activities. This sometimes creates a good obstacle for the hospital side, especially for the patient side, therefore in this study a system that emphasizes more on the automation system of treatment that is carried out centrally will be designed.

Following up the current bureaucracy using several types, the system will be made to adjust to the ongoing deregulation. In general, a review can be seen in Figure 2 below:

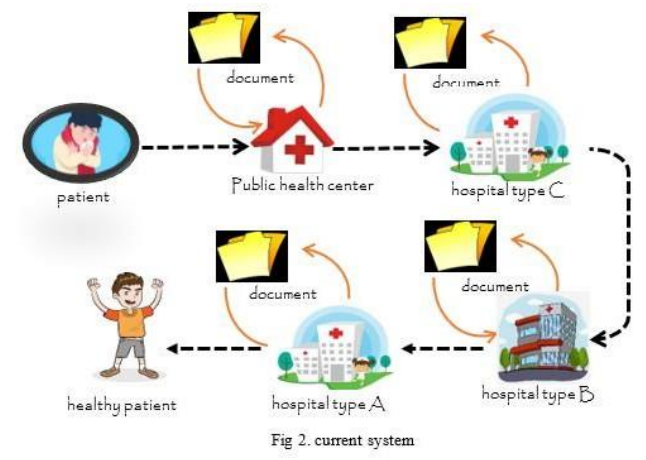




\section{Kresna Social Science and Humanities Research \\ Proceedings of the International Conference On Ummah: \\ Digital Innovation, Humanities And Economy (ICU: DIHEc) 2020 \\ https://doi.org/1030874/ksshr.71}

Based on Figure 2 above, it can be described that each patient will be admitted to the upper hospital (the higher type) must complete the supporting documents which may be a large number. Not to mention that patients are required to register in a queuing system with a huge queue.

In the design of the system to be designed, the documentation system for each entity will be eliminated (registration to a referral hospital). Patients who carry out the engagement process only need to do the filing at the public health center, if the patient is going to be referred to the hospital, the patient only comes based on the scheduled treatment time in the system. Patients come without having to bring supporting documents, this has been registered using the system. So that we get an image on the system depicted in Figure 3 below:

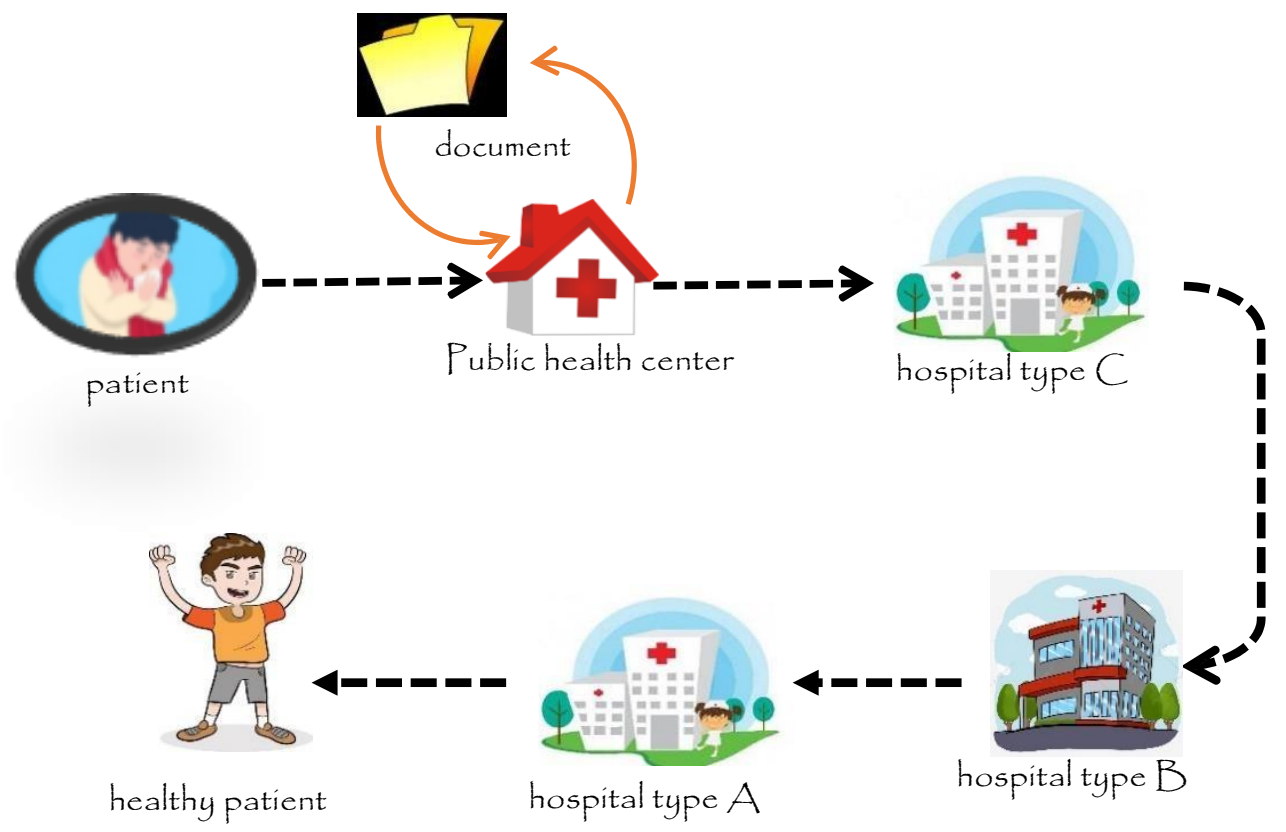

Fig 3. futura system

In Figure 3 above, it is explained that the filing process is carried out at the public health center only. And the system at the next few hospitals only accepts data from the previous referring hospitals.

Based on the design above, the data flow can be described based on the design of Figure 4 below:

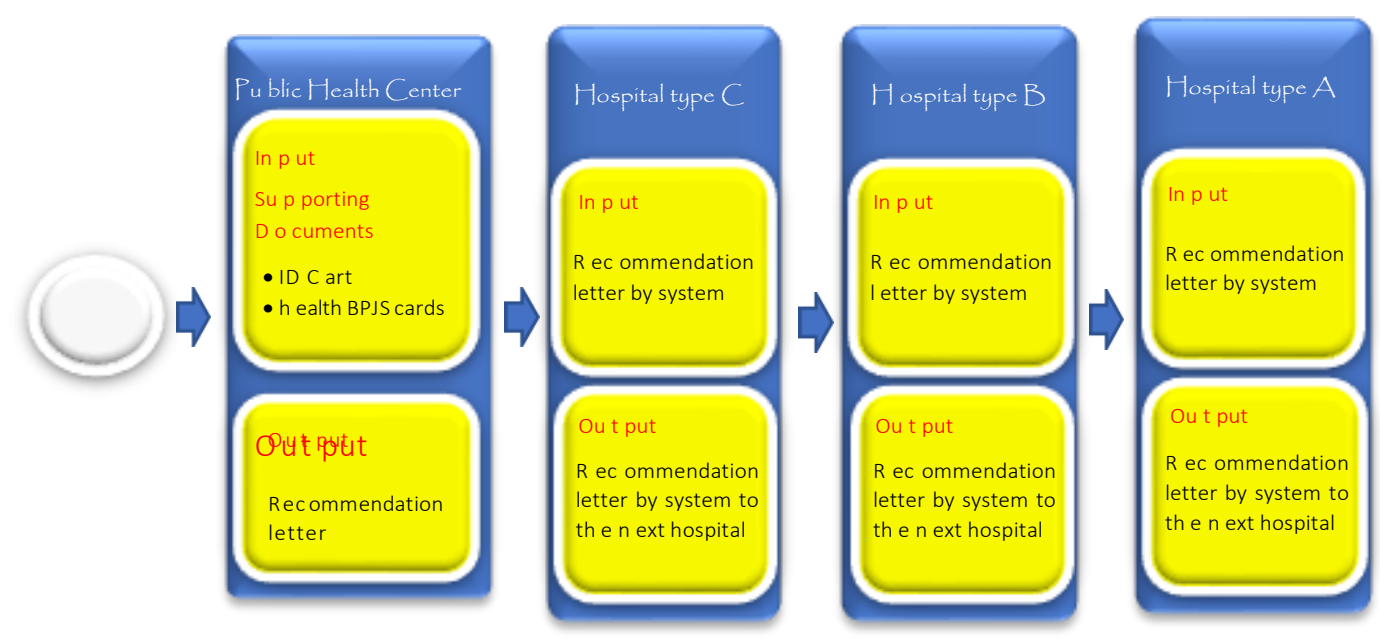

Fig 4. the document system is running 
Based on the running of the documents, the initial stage of the patient must be treated at the hospital according to the BPJS regulations and bring supporting documents. After verification, the patient will carry out the check-up stage at the clinic (initial type hospital), after getting the results and must be referred to the upper hospital (type $\mathrm{C}$ ) for further treatmen $\mathrm{t}$, the hospital must enter into the system and set the schedule and which hospital to use. will be addressed according to regulations, and send supporting documents to the referral hospital online. Then the patient can go directly to the referral hospital without having to bring supporting documents to the referral hospital and has received a queue number based on the system, the time (day and date and hour) and the intended doctor (specialist doctor) are shown in the queue number. After the patient comes to the hospital, he can go directly to the doctor in question and get the service he should. In the treatment process, if you have to get a referral to a hospital above it, the hospital administration can send patient data by system to the referral hospital, with the same data the referral hospital system sends data to the referral hospital. In the same way, patients carry out instructions to referral hospitals without having to bring supporting documents, because the complete documents have been sent to the referral hospital system. The patient only has to come to the referral hospital according to the queue number which contains the time, hour, and the doctor. The same applies if the patient must undergo inpatient and outpatient treatment (timing of control).

\section{Conclusion}

Based on the design, a documentation system is applied at an early stage and for the next type of hospital, it only gets data on the initial hospital data. The concept emphasizes patient care. Where patients do not need to bring a size document for treatment to a referral hospital, even the medical schedule has been done automatically on the system. Pasiah only comes to the referral hospital based on a schedule that has been designed by the system, by coordinating with the patient beforehand.

\section{References}

[1] Journal Article: Demokaan Demirel, Hospital Management Information Systems in Health Sector and Development in Turkey, ournal of Current Researches on Hea lth Sector, Vol 7, December 2018

[2] Journal Article:Schaefermeyer M, Rosenkranz C, Holten R. Theimpact of business process complexity on business process standardization - Anempirical study. Business \& Information Systems Engineering. 2012; 4 (5) : $261-270$.

[3] Journal Article:Schaefermeyer M,Rosenkranz C,Holten R. Theimpact of business process complexity on business process standardization - Anempirical study. Business \& Information Systems Engineering. 2012;4 (5):261-270

[4] Journal Article: GebauerJ, LeeF. Enterprise system flexibility and implementations trategies: aligning theory with evidence from a casestudy. Information Systems Management.2008;25(1):71-82.

[5] Journal Article:Overby EM. Process virtualization theory and the impact of information technology. Organization Sci-ence. 2008; 19 (2): 277-291

[6] Journal Article: Silic M, Barlow J, Back A. 2018.Evaluating the role of trust in adoption: a conceptualreplication in the context of open source systems.AIS Transactions on ReplicationResearch4(1):1 -17 DOI 10.17705/1atrr.00021.

[7] Book: Thatcher JB, McKnight DH, Baker EW, Arsal RE, Roberts NH. 2011.The role oftrust in postadoption IT exploration: an empirical examination of knowledgemanagement systems.IEEE Transactions on Engineering Management58(1):56-70DOI 10.1109/TEM.2009.2028320.

[8] Journal Article: Waldrop MM. 2016.The chips are down for Moore's law.Nature530(7589):144-147DOI 10.1038/530144a. 
[9] Journal Article: Wenzel R, Van Quaquebeke N. 2018. The double-edged sword of big data in organiza-tional and management research.Organizational Research Methods21(3):548-591DOI 10.1177/1094428117718627.

[10] Journal Article: Aralova N. I., Klyuchko O. M. Mathematic modeling of functional self-organization of pilots' respiratory systems. "Integrated intellectual robototechnical complexes"- "IIRTC-2018". Materials of XI Intl. Scient.Tech. Conference, 2018. P. 268-269. (In Ukrainian).

[11] Journal Article: Klyuchko O. M., Piatchanina T.V., Ma -zur M. G., Basarak O. V. Ontological methods in the development of biomedical information systems. "Integrated intellec tual robototechnical complexes"- "IIRTC-2018": Materials of XI Intl. Scient.Tech. Conference, 2018. P. 270-272. (In Ukrainian).

[12] Journal Article: Klyuchko O. M., Tzal-Tzalko V. I. Elaboration of new monitoring system for Ukrainian Polissia conditions with data defence. Bull. Engin. Acad. 2014, 2. P. 239-246. (In Ukrainian).

[13] Journal Article: Klyuchko O. M., Hayrutdinov R. R. Modeling of electrical signals propagation in neurons and its nanostructures. Electr. Contr. Syst. 2011, 2 (28), 120124. (In Ukrainian).

[14] Journal Article: Klyuchko Z. F., Klyuchko E. M. Moth (Lepidoptera: Noctuidae s. 1.) of Chercasska region of Ukraine according to results of many-year monitoring. Eversmannia. 2014, No 37, 32-49. (In Russian).

[15] Journal Article: Klyuchko Z. F., Klyuchko E. M. Analysis of taxonomic structure of moth fauna (Lepidoptera: Noctuidae s.l.) of Ukraine according to monitoring data. Eversmannia, 2012, 3 (33), 41-45. (In Russian).

[16] A Journal Article: bu-Dalbouh HM. 2013.A questionnaire approach based on the technology acceptancemodel for mobile tracking on patient progress applications.Journal of ComputerScience9(6):763-770 DOI 10.3844/jcssp.2013.763.770

[17] Journal Article: Blaya JA, Fraser HS, Holt B. 2010.E-health technologies show promise in developingcountries.Health Affairs29(2):244-251 DOI 10.1377/hlthaff.2009.0894.

[18] Journal Article: Dormekpor E. 2015.Poverty and gender inequality in developing countries.DevelopingCountry Studies5(10):76-102

[19] Journal Article: Eneji MA, Juliana DV, Onabe BJ. 2013.Health ca re expenditure, health status andnational productivity in Nigeria (1999 -2012).Journal of Economics and InternationalFinance5(7):258-272 DOI 10.5897/JEIF2013.0523.

[20] Journal Article: Hoque MR, Mazmum M, Bao Y.2014.e-Health in Bangladesh: current status, chal-lenges, and future direction.The International Technology Management Review4(2):87-96 DOI 10.2991/itmr.2014.4.2.3.

[21] Journal Article: Kabashiki IR, Moneke NI. 2014.The impact of the use of hea lth information andcommunication technology on health care delivery in Manitoba, Canada.Journalof Hospital Administration3(6):8 -19 DOI 10.5430/jha.v3n6p8

[22] Journal Article: Lee HW, Ramayah T, Zakaria N. 2012.External factors in hospital informationsystem (HIS) adoption model: a case on Malaysia.Journal of Medical Systems36(4):2129-2140 DOI10.1007/s10916-011-9675-4.

[23] Journal Article: Luna D, Almerares A, Mayan JC, Bernaldo FG, Otero C. 2014.Health informatics indeveloping countries: going beyond pilot practices to sustainable implementa-tions: a review of current challenges.Healthcare Informatics Research20(1):3-10DOI 10.4258/hir.2014.20.1.3

[24] Journal Article: Malaquias RF, De Oliveira Malaquias FF, Hwang Y. 2017.The role of information andcommunication technology for development in Brazil.Information Technology forDevelopment23(1):179-193 DOI 10.1080/02681102.2016.1233854

[25] Journal Article: Melas CD, Zampetakis LA, Dimopoulou A, Moustakis V. 2011.Modeling theacceptance of clinical information systems among hospital medical staff:an extended TAM model.Journal of Biomedical Inform atics44(4):553-564DOI 10.1016/j.jbi.2011.01.009 To view a copy of this license, visit https://creativecommons.org/licenses/by/4.0/. 
Kresna Social Science and Humanities Research

Proceedings of the International Conference On Ummah:

Digital Innovation, Humanities And Economy (ICU: DIHEc) 2020

$$
\text { https://doi.org/1030874/ksshr.71 }
$$

[26] Journal Article: Quaglio G, Schellekens A, Blankers M, Hoch E, Karapiperis T, Esposito G, Brand H,Nutt D, Kiefer F. 2017.A brief outline of the use of new technologies for treating substance use disorders in the European Union.European Addiction Research23:177-181 DOI 10.1159/000478904.

[27] Journal Article: Steininger K, Stiglbauer B. 2015.EHR acceptance among Austrian resident doctors.Health Policy and Technology4(2):121 -130 DOI 10.1016/j.hlpt.2015.02.003.

[28] Journal Article: Tome L, Johnston KA, Meadows A, Nyemba -Mudenda M. 2014.Barriers to open sourceERP adoption in South Africa.African Journal of Information Systems6(2):26-47.Uluc NC, Ferman M. 2016.A comparative analysis of user insights for e-healthdevelopment challenges in Turkey, Kingdom of Saudi Arabia, Egypt andUnited Arab Emirates.Journal of Management and Logistics3(2):176-189DOI 10.17261/Pressacademia.2016219945. 